\title{
ACUTE KIDNEY INJURY IN HOSPITALIZED PATIENTS FREQUENCY OF VARIOUS ETIOLOGIES.
}

1. MBBS, FCPS

Assistant Professor

Department of Medical Unit IV,

Nishtar Hospital Multan.

2. M.Sc

Research Officer

PHRC, Multan.

2. MBBS, FCPS

Senior Registrar

Department of Medicine

NMU Multan.

Correspondence Address:

Dr. Shahzad Alam Khan

Department of Medicine

Nishtar Medical University, Multan.

shahzadalam17735@gmail.com

Article received on:

$11 / 04 / 2018$

Accepted for publication:

25/07/2019

\begin{abstract}
Shahzad Alam Khan ${ }^{1}$, Ahsan-Ullah Mirbahar ${ }^{2}$, Mehboob Qadir ${ }^{3}$
ABSTRACT... Objectives: To identify magnitude of various etiologies causing acute kidney injury (AKI) in hospital admitted patients at Nishtar hospital, Multan. Study Design: Cross sectional observational study. Setting: Medical Unit-IV, Nishtar Hospital and Medical University, Multan. Period: The study span was six month extending from February 2018 to July 2018. Material and Methods: In our setting, we took a sample of 383 patients admitted to medical unit- IV for variety of medical conditions using non-probability purposive sampling technique. Patients having an age range of 30-70 years and either gender were taken. Those patients who had previously deranged kidney functions, Reno grafting, snake envenomation and kalapathar (PPD) poisoning were not considered for study. Results: The age of patients ranged from 36 years to 62 years and had a mean of $47.94 \pm 8.14$ years. There were $54 \%$ male and $46 \%$ female patients in our setting. The most common presenting medical disorders requiring indoor admission were pulmonary diseases seen in $38.9 \%$ patients then hepatobiliary disorders $27.4 \%$, infections $24 \%$ and diabetes $9.6 \%$. Out of 383 patients, $107(27.9 \%)$ patients had AKI. It was more prevalent $(p=0.000)$ diabetic patients $46 \%$, hepatobiliary disorders $36.1 \%$, infectious diseases $27.1 \%$ and then respiratory tract diseases $18.1 \%$. While working on etiological causes of $\mathrm{AKI}$, we found drugs were frequent inciting factor, present in $39.3 \%$ patients then was sepsis $19.6 \%$, volume loss $17.7 \%$ and hypotension $8.5 \%$. Combined fluid depletion plus sepsis was noted in $6.5 \%$ patients followed by sepsis plus drugs in $4.6 \%$ and sepsis plus drugs plus hypotension seen in $3.7 \%$ patients. However, drugs were major contributory factor of AKI in patients having hepatobiliary diseases $65.8 \%$ and diabetes $35.3 \%$. In patients of respiratory tract diseases having AKI, fluid loss $36.0 \%$ and sepsis $28.6 \%$ were recurring findings. Among patients of infectious diseases, sepsis $40 \%$ and drugs $28 \%$ were more common. Conclusion: Occurrence of Acute kidney injury among hospitalized patients was statistically significant $(p=0.000)$ in patients with diabetes mellitus and hepatobiliary disease at the time of admission. While noting etiological factors, it was seen that drugs were the most prevalent followed by septicemia, then hypovolemia among the factors responsible for AKI.
\end{abstract}

Key words: $\quad$ Acute Kidney Injury, Etiological Causes, Hospital Admitted Patients.

Article Citation: Khan SA, Mirbahar A, Qadir M. Acute kidney injury in hospitalized patients frequency of various etiologies. Professional Med J 2019; 26(11):19521957. DOI: 10.29309/TPMJ/2019.26.11.3544

\section{INTRODUCTION}

Acute renal failure (ARF) and Acute Kidney Injury (AKI) signify disease complex which occur in the background of different medical catastrophes and manifests itself in any way like minimal rise in serum creatinine to complete cessation of urine. Most of the time it remains under-diagnosed and then results in adverse outcomes. ${ }^{1}$ Clinical complex leading to fall in glomerular filtration rate (GFR) and urine output is essentially labeled as acute kidney injury (AKI). ${ }^{2}$ Acute kidney injury(AKI) is common in the background of other medical disorder and is responsible for high mortality in these conditions. ${ }^{3}$ The prevalence of AKI is showing up soaring trend and risk of death is still high despite of massive research efforts. $^{4-5}$ It becomes essentially significant to identify the underlying causes of ARF, as outcome is greatly influenced by specific underlying etiology. ${ }^{6}$ Epidemiological surveys may be helpful to chalk out planning and develop ways to identify controllable and reversible factors causing ARF. ${ }^{7}$ ARF related to obstetric diseases and fluid depletion from gut are examples of reversible and controllable causes. ${ }^{8}$ It's a dilemma that these frequently encountered conditions are more 
common in the developing as compared to the developed countries. ${ }^{9}$

$\mathrm{AKI}$ is more frequently seen in hospitalized settings in comparison to community settings. ${ }^{10}$ In hospitalized patients, AKI tends to be a grave manifestation where it occurs in combination of various co morbidities and it reaches at a frequency of $20 \%$ to $40 \%$. $^{11}$

In 2013, Schissler et al ${ }^{12}$ studied different causes of $\mathrm{AKI}$ and suggested that volume loss (26.4\%) and drugs (17.2\%) are the most frequent etiologies leading to AKI. Singh et al. ${ }^{13}$ in 2013 found that drugs $39.2 \%$, septicemia $19.6 \%$, fluid loss $17.8 \%$, hypotension $7.8 \%$ are commonly encountered factors responsible for AKI.

By providing optimal care and expedient management, it is possible to minimize risk of AKI and in turn minimizing morbidity and mortality. ${ }^{14}$ As Nishtar hospital, Multan is the largest medical institute in South Punjab and so far, no study has been done here to identify reversible causative factors of AKI. The results of this study may then be generalized to identify patient population having risk of $\mathrm{AKI}$ and also etiological causes which endanger the patients for AKI. By doing so, in time intervention and planning steps can be taken in order to avoid undue morbidity and mortality linked to AKI.

\section{MATERIALS AND METHOD}

In our setting, we took a sample of 383 patients admitted to medical unit- IV for variety of medical conditions using non-probability purposive sampling technique. Patients having an age range of 36- 62 years and either gender were taken. The study span was six month extending from February 2018 to July 2018. Those patients who had previously deranged kidney functions, Reno grafting, snake envenomation and kalapathar (PPD) poisoning were not considered for study. Once included in study, the $1^{\text {st }}$ level of serum creatinine was labeled as the base line value. Persistence of serum creatinine above $2 \mathrm{mg} / \mathrm{dl}$ $(177 \mu \mathrm{mol} / \mathrm{L})$ on two blood samples drawn with 12 hours interval, in spite of resuscitation for any hemodynamic or mechanical compromise was labeled as Acute Renal Failure (ARF). History, physical examination and investigations were carried out to reach the cause of acute renal failure.

To identify the etiology of ARF, we applied different clinical criteria. Fall in blood pressure less than $90 / 60 \mathrm{mmHg}$, postural hypotension and signs of fluid loss were indicative of renal hypo perfusion.

Drug induced nephrotoxicity was causative factor if a patient took any of known nephrotoxic medicine for at least 3 days during his/her hospital stay. Sepsis was considered in those who had positive blood culture or fever $>100^{\circ} \mathrm{F}\left(37.5^{\circ} \mathrm{C}\right)$ and associated with TLC $>10 \times 10^{9} /$ L. Presence of urinary sodium $<10 \mathrm{mEq} / \mathrm{L}$ in a patient severe liver failure was thought to have hepatorenal syndrome. All data were entered in a pre - tested, pre designed and validated proforma.

The data analysis was done by using SPSS-version 24. Frequencies were calculated for qualitative variables such as diabetes, hypotension, sepsis, respiratory illness, hepatobiliary diseases, gender and acute kidney injury while mean and standard deviation were evaluated for the age of sample patients. Association of various underlying factors with AKI were ascertained by applying Chi-square test and keeping confidence level 95\%.

\section{RESULTS}

The age of patients in our study ranged from 36 years to 62 years and had a mean of $47.94 \pm 8.14$ years. There were $54 \%$ male and $46 \%$ female patients in our setting. The most common presenting medical disorders requiring indoor admission were respiratory tract disease seen in $38.9 \%$ patients then hepatobiliary disorders $27.4 \%$, infections $24 \%$ and diabetes $9.6 \%$ as shown in Table-l.

Out of 383 patients, 107(27.9\%) patients had AKI. It was more prevalent $(p=0.000)$ diabetic patients $46 \%$, hepatobiliary disorders $36.1 \%$, infectious diseases $27.1 \%$ and then pulmonary diseases $18.1 \%$ (Table-II). However, statistical difference in the rate of $\mathrm{AKI}$ in male versus female was not pronounced (25.8\% vs. $28.6 \%$; $p=0.525$ ). 
While working on etiological causes of AKI, we found drugs were frequent inciting factor, present in $39.3 \%$ patients then was septicemia $19.6 \%$, fluid loss $17.7 \%$ and low BP $8.5 \%$. Combined fluid depletion plus septicemia was noted among $6.5 \%$ patients followed by septicemia plus drugs/ medication in $4.6 \%$ and septicemia plus drugs plus low BP seen in $3.7 \%$ patients (Table-III).

There was little statistical difference with regard to age $(p=0.153)$ and gender $(p=0.371)$ when stratification of the responsible factors against age and sex was done. However, drugs were major contributory factor of $\mathrm{AKI}$ in patients having hepatobiliary diseases $65.8 \%$ and diabetes $35.3 \%$. In patients of respiratory tract diseases having AKI, fluid loss $36.0 \%$ and septicemia $28.6 \%$ were recurring findings. Among patients hospitalized with infectious diseases, septicemia (40\%) and drugs (28\%) were more common. The difference observed was significant statistically having $\mathrm{p}<0.000$. (Table-IV).

\begin{tabular}{|l|c|c|}
\hline \multicolumn{1}{|c|}{ Medical Disease at Admission } & Frequency & Percentage \\
\hline Hepatobiliary Disorders & 105 & 27.4 \\
\hline Pulmonary diseases & 149 & 38.9 \\
\hline Infectious diseases & 92 & 24 \\
\hline Diabetes mellitus & 37 & 9.6 \\
\hline Total Patients & 383 & 100.0 \\
\hline
\end{tabular}

Table-I. Frequency of various medical disorders enforcing hospital admission

\begin{tabular}{|c|c|c|c|c|c|}
\hline \multirow[b]{2}{*}{ AKI } & \multicolumn{4}{|c|}{ Medical Disorders Enforcing Admission $(n=383)$} & \multirow[b]{2}{*}{ P-Value } \\
\hline & $\begin{array}{c}\text { Hepatobiliary } \\
\text { Disorders }\end{array}$ & $\begin{array}{l}\text { Pulmonary } \\
\text { diseases }\end{array}$ & $\begin{array}{l}\text { Infectious } \\
\text { diseases }\end{array}$ & $\begin{array}{l}\text { Diabetes } \\
\text { mellitus }\end{array}$ & \\
\hline Yes $(n=107)$ & $38(36.1 \%)$ & $27(18.8 \%)$ & 25 (27.1\%) & 17 (46\%) & \multirow{3}{*}{0.000} \\
\hline No $(n=276)$ & $67(63.8 \%)$ & $122(81.2 \%)$ & $67(72.8 \%)$ & $20(54 \%)$ & \\
\hline Total & $105(100 \%)$ & $149(100 \%)$ & $92(100 \%)$ & $37(100 \%)$ & \\
\hline
\end{tabular}

\begin{tabular}{|l|c|c|}
\hline \multicolumn{1}{|c|}{ Responsible Factors } & Frequency & Percentage \\
\hline Fluid loss/Hypovolemia & 19 & 17.7 \\
\hline Drugs/Medication & 42 & 39.3 \\
\hline Septicemia & 21 & 19.6 \\
\hline Low BP & 9 & 8.4 \\
\hline Fluid Loss plus Sepsis & 7 & 6.5 \\
\hline Septicemia plus Drugs & 5 & 4.6 \\
\hline Drugs plus Hypotension plus Sepsis & 4 & 3.7 \\
\hline Total & 107 & 100 \\
\hline
\end{tabular}

Table-III. Frequency of various etiological factors

\begin{tabular}{|c|c|c|c|c|c|}
\hline \multirow{2}{*}{ Responsible Factors } & \multicolumn{3}{|c|}{ Underlying medical disorders enforcing admission (n=107) } \\
\cline { 2 - 4 } & $\begin{array}{c}\text { Hepatobiliary } \\
\text { Disorders }\end{array}$ & $\begin{array}{c}\text { Pulmonary } \\
\text { Diseases }\end{array}$ & $\begin{array}{c}\text { Infectious } \\
\text { Diseases }\end{array}$ & $\begin{array}{c}\text { Diabetes } \\
\text { Mellitus }\end{array}$ & \multirow{2}{*}{ P-Value } \\
\hline Fluid Loss & $4(10.5 \%)$ & $10(36.0 \%)$ & $3(12 \%)$ & $1(5.8 \%)$ \\
\hline Medication/Drugs & $25(65.8 \%)$ & $4(15.8 \%)$ & $7(28 \%)$ & $6(35.3 \%)$ \\
\hline Septicemia & $1(2.6 \%)$ & $8(28.6 \%)$ & $10(40 \%)$ & $2(11.7 \%)$ \\
\hline Low BP & $1(2.6 \%)$ & $3(12.2 \%)$ & $2(8 \%)$ & $2(11.7 \%)$ & \multirow{2}{*}{0.000} \\
\hline Fluid loss plus Sepsis & $3(7.8 \%)$ & $1(3.7 \%)$ & $2(8 \%)$ & $3(17.6 \%)$ & \\
\hline Septicemia plus Drugs & $3(7.8 \%)$ & $1(3.7 \%)$ & $1(4 \%)$ & NIL & \\
\hline Septicemia plus Drugs plus Low BP & $1(2.6 \%)$ & NIL & NIL & $3(17.6 \%)$ \\
\hline Total & $38(100 \%)$ & $27(100 \%)$ & $25(100 \%)$ & $17(100 \%)$ \\
\hline
\end{tabular}

Table-IV. Comparison of etiological factors across different underlying medical conditions 


\section{DISCUSSION}

Acute kidney injury (AKI) is overburdening and exhausting health care facilities and resources. However, AKI is frequently being encountered in hospital settings rather than in the community. In hospital admitted patients, AKI is a grave situation when it is accompanied by other co morbid health issues that coexist in $20 \%$ to $40 \%$ of the cases. ${ }^{15}$ In our study, 107 (27.9\%) patients had AKI. Our results closely resemble with results of Coca et $\mathrm{al} ;{ }^{16}$ who noticed $26.6 \%$ frequency in US population and Medve and Gondos ${ }^{17}$ found $24.4 \%$ frequency of $\mathrm{AKI}$ in Hungarian people. The intention to conduct this study was to find out the frequency of various etiologies causing AKI in tertiary hospital settings.

The age of cases in our study ranged from 36 years to 62 years and had a mean of $47.94 \pm 8.14$ years. Mean age of patients which Schissler et $\mathrm{al}^{12}$; noticed in American population having indoor admission related AKI was $69.5 \pm 11.1$. This difference is believed to be due to longer life span of Americans. In our setting, we had $54 \%$ males and $46 \%$ females. Wang et al ${ }^{18}$; in (2012) had also seen a slightly high male predominance $(51.9 \%$ vs. $48.1 \%$ ) of AKI in American Population. Wang et $\mathrm{al}^{18}{ }^{18}$ also noted that the among the underlying causes enforcing hospital admission commonest was pulmonary diseases seen in $39.9 \%$ patients, then hepatobiliary disorders $26.4 \%$, infectious diseases $23.8 \%$ and diabetes mellitus $9.9 \%$. Our findings resembles with that of Schissler et al ${ }^{12}$; who observed pulmonary diseases in $39.6 \%$ of admitted patients. In another study, AKI was noticed in patients with pulmonary diseases at a rate of $30 \%$ at the moment of ICU admission. ${ }^{19}$ In Indian study conducted in 2013 by Singh et $\mathrm{al}^{13}$; noticed somewhat similar frequencies i.e. hepatobiliary disorders $25.49 \%$, infectious diseases $21.57 \%$ and diabetes mellitus $3.92 \%$. Upon identification of individual risk factors instigating $\mathrm{AKI}$, drugs were predominant, seen in $39.3 \%$ patients then septicemia in $19.6 \%$ patients and fluid loss/hypovolemia in $17.7 \%$ patients. In India Reddy KT et al; ${ }^{20}$ collected data of ICU admitted patients having AKI and found sepsis in $32 \%$, fluid loss in $61.3 \%$ of patients causing acute renal failure . Kim MH et al; ${ }^{21}$ found that AKI was more common in patients admitted with respiratory disease up to $50.5 \%$ followed by diabetes mellitus up to $26.1 \%$ and those with liver disease frequency was $20.8 \%$. lavecchia $L$ et $\mathrm{al}^{22}$, has identified that drugs contribute to $54.1 \%$ cases of AKI in hospitalized patients.

Combined fluid loss plus sepsis was noticed in $6.5 \%$ patients followed by septicemia plus drugs in $4.6 \%$ and septicemia plus drugs plus hypotension in $3.7 \%$ patients. In another Indian study Singh et al ${ }^{13}$ noted frequencies of various causes of AKI like drugs $14.8 \%$, sepsis $53.1 \%$, volume loss $6.5 \%$. Davenport A et al; ${ }^{23}$ noted that impaired renal function occurs in $25 \%$ to $50 \%$ of cirrhotic patients having acute hepatic decompensation.

When the etiological factors instigating AKI were stratified, difference with respect to age $(p=0.172)$ and sex $(p=0.431)$ was statistically insignificant. However, drugs contributed to majority of AKI cases in patients having hepatobiliary disorders i.e. $65.7 \%$ and diabetes mellitus i.e. $38.9 \%$. Patients having pulmonary diseases developed AKI in the background of fluid loss ( $37.0 \%$ cases) and septicemia (29.6\% cases). Patients admitted with infectious diseases developed AKI more frequently due to septicemia ( $37.5 \%$ cases) and drugs (29.2\% cases). The difference was statistically pronounced $(p=0.000)$. Ali et al. ${ }^{24}$ conducted a study in Northern Scotland and found septicemia was a predisposing factor in $47 \%$ of patients and fluid loss up to $32 \%$. Bagshaw et al ${ }^{25}$ also noted sepsis in $42.1 \%$ of AKI patients. Martin GS et al: ${ }^{26}$ noticed that sepsis contributed to AKI in $15 \%$ patients and the results were very much similar to our results as we noted septicemia as precipitant cause in $19.2 \%$ patients.

Our study is unique in a sense as it is first of its kind in local population. It will provide solid baseline data regarding frequency of different instigating factors causing AKI. We observed that presences of few instigating factors in association with certain peculiar medical disorders are more hazardous regarding AKI acquisition. Once identified measures can be taken to decrease the load of AKI in hospital settings just by avoiding 
that particular instigating factor.

\section{CONCLUSION}

Acute kidney injury is an serious threat among hospital admitted patients. Occurrence of Acute kidney injury among hospitalized patients was statistically significant $(p=0.000)$ in patients with diabetes mellitus and hepatobiliary disease at the time of admission. While noting etiological factors, it was seen that drugs were the most prevalent followed by septicemia, then hypovolemia among the factors responsible for AKI. Drugs cause more serious harms in patients with hepatobiliary diseases and diabetes. Fluid loss and septicemia are more injurious to cause $\mathrm{AKI}$ in patients with pulmonary diseases. Taking into account of all above data regarding precipitating medical conditions and etiological factors we can chalk out plan to reduce the magnitude of the problem and longer indoor stay of the patients.

Copyright@ 25 July, 2019.

\section{REFERENCES}

1. Palevsky PM: Epidemiology of acute renal failure: The tip of the iceberg. Clin J Am Soc Nephrol 2006, 1: 6-7.

2. Bellomo R, Ronco C, Kellum JA, Mehta RL, Palevsky $\mathrm{P}$; Acute dialysis quality initiative workgroup. Acute renal failure - definition, outcome measures, animal models, fluid therapy and information technology needs: The second international consensus conference of the acute dialysis quality initiative (ADQI) group. Crit Care 8: R204- R212, 2004.

3. De Corte W, Dhondt A, Vanholder R, De Waele J, Decruyenaere J, Sergoyne V, Vanhalst J, Claus S, Hoste EA. Long-term outcome in ICU patients with acute kidney injury treated with renal replacement therapy: A prospective cohort study. Crit Care 20: 256, 2016.

4. Hsu RK, McCulloch CE, Dudley RA, Lo LJ, Hsu CY. Temporal changes in incidence of dialysis-requiring AKI. J Am Soc Nephrol 24: 37-42, 2013.

5. Ympa YP, Sakr Y, Reinhart K, Vincent JL. Has mortality from acute renal failure decreased? A systematic review of the literature. Am J Med 118: 827-832, 2005.

6. Kaddourah A, Basu RK, Bagshaw SM, Goldstein SL. Epidemiology of acute kidney injury in critically ill children and young adults. N Engl J Med. 2017 Jan 5; 376(1):11-20.
7. Dare AJ, Fu SH, Patra J, Rodriguez PS, Thakur JS, Jha $P$, Million death study collaborators. Renal failure deaths and their risk factors in India 2001-13: Nationally representative estimates from the Million Death Study. The Lancet Global Health. 2017 Jan 1; 5(1):e89-95.

8. Shapiro SR, Bennett AH. Recovery of renal function after prolonged unilateral ureteral obstruction. J Urol 1976; 115(2):136-40.

9. Chugh KS, Sakhuja V, Malhotra HS, Pereira BJ. Changing trends in acute renal failure in thirdworld countries--Chandigarh study. Q J Med 1989; 73(272):1117-23.

10. Liano F, Pascual J. Epidemiology of acute renal failure: A prospective, multicenter, community-based study. Madrid Acute Renal Failure Study Group. Kidney Int. 1996; 50:811-8.

11. Prakash J, Singh TB, Ghosh B, Malhotra V, Rathore SS, Vohra R, et al. Changing epidemiology of communityacquired acute kidney injury in developing countries: Analysis of 2405 cases in 26 years from eastern India. Clin Kidney J. 2013; 6(2):150-5.

12. Schissler MM, Zaidi S, Kumar H, Deo D, Brier ME, McLeish KR. Characteristics and outcomes in community-acquired versus hospital-acquired acute kidney injury. Nephrology (Carlton). 2013; 18(3):183-7.

13. Singh TB, Rathore SS, Choudhury TA, Shukla VK, Singh DK, Prakash J. Hospital-acquired acute kidney injury in medical, surgical, and intensive care unit: A comparative study. Indian J Nephrol. 2013; 23(1):24-9.

14. Luo $X$, Jiang $L$, Du B, Wen $Y$, Wang $M$, Xi X. Acute Kidney Injury Trial (BAKIT) workgroup. A comparison of different diagnostic criteria of acute kidney injury in critically ill patients. Crit Care. 2014; 18(4):R144.

15. Lewington AJ, Cerdá J, Mehta RL. Raising awareness of acute kidney injury: A global perspective of a silent killer. Kidney Int. 2013; 84(3):457-67.

16. Coca SG, Yalavarthy R, Concato J, Parikh CR. Biomarkers for the diagnosis and risk stratification of acute kidney injury: A systematic review. Kidney Int. 2008; 73:1008-16.

17. Medve L, Antek C, Paloczi B, Kocsi S, Gartner B, Marjanek Z, et al. Epidemiology of acute kidney injury in Hungarian intensive care units: A multicenter, prospective, observational study. BMC Nephrol. $2011 ; 12: 43$. 
18. Wang $Y$, Cui $Z$, Fan M. Retrospective analysis on Chinese patients diagnosed with acute renal failure hospitalized during the last decade (1994-2003). Am J Nephrol. 2005; 25:514-9.

19. de Abreu Krasnalhia Lívia Soares, da Silva Geraldo Bezerra Junior. Acute kidney injury in critically ill patients with lung disease: Kidney-lung crosstalk. Rev Bras Ter Intensiva. 2013; 25: 130-36.

20. Reddy KT, Sharada EV, Krishnan S. Acute renal failure in intensive care unit. J Indian Med Assoc. 2009 Mar; 107(3):160-3.

21. Kim MH, Koh SO, Kim EJ. Incidence and outcome of contrast-associated acute kidney injury assessed with Risk, Injury, Failure, Loss, and Endstage kidney disease (RIFLE) criteria in critically ill patients of medical and surgical intensive care units: A retrospective study. BMC Anesthesiol. 2015 Mar 3; $15: 23$
22. lavecchia L, Cereza García G, Sabaté Gallego M, et al. Drug-related acute renal failure in hospitalized patients. Nefrologia. 2015; 35(6):523-532.

23. Davenport A, Sheikh MF, Lamb E et al. Acute kidney injury in acute-on-chronic liver failure: Where does hepatorenal syndrome fit? Kidney Int. 2017 Nov; 92(5):1058-1070.

24. Ali T, Khan I, Simpson W. Incidence and outcomes in acute kidney injury: A comprehensive populationbased study. J Am Soc Nephrol. 2007; 18:1292-8.

25. Bagshaw SM, George C, Bellomo R; ANZICS database management committee. Early acute kidney injury and sepsis: A multicentre evaluation E. Crit Care. 2008; 12(2):R47.

26. Martin GS, Mannino DM, Eaton $S$, et al. The epidemiology of sepsis in the United States from 1979 through 2000. N Engl J Med. 2003 Apr 17; 348(16):1546-54.

\begin{tabular}{|c|c|c|c|}
\hline \multicolumn{3}{|c|}{ AUTHORSHIP AND CONTRIBUTION DECLARATION } \\
\hline Sr. \# & Author(s) Full Name & \multicolumn{1}{c|}{ Contribution to the paper } & Author(s) Signature \\
\hline 1 & Shahzad Alam Khan & $\begin{array}{l}\text { Study planning, Designing, } \\
\text { Manuscript writing, Data } \\
\text { collection. } \\
\text { Data analysis and Proof } \\
\text { reading. } \\
\text { Data collection, Co-ordination } \\
\text { with Co-author. }\end{array}$ \\
\hline 3 & Ahsan-Ullah Mirbahar \\
\hline
\end{tabular}

